\title{
MULTI-OBJECTIVE OPTIMIZATION OF PROCESS PARAMETERS FOR POWDER MIXED ELECTRICAL DISCHARGE MACHINING OF INCONEL X-750 ALLOY USING TAGUCHI-TOPSIS APPROACH
}

\author{
BASHA Shaik Khadar ${ }^{1,3}$, RAJU M. V. Jagannadha1, KOLLI Murahari2 ${ }^{2}$ \\ ${ }^{I}$ College of Engineering Andhra University, Department of Mechanical Engineering, Vishakapatnam, \\ Andhra Pradesh, India \\ 2*Department of Mechanical Engineering, Lakireddy Bali Reddy College of Engineering, Mylavaram, \\ Andhra Pradesh, India, e - mail: kmhari.nitw@gmailcom \\ ${ }^{3}$ Department of Mechanical Engineering, Koneru Lakshmaiah Education Foundation, Green Fields, \\ Vaddeswaram, Guntur District, Andhra Pradesh, India
}

\begin{abstract}
The paper investigates the influence of boron carbide powder $\left(\mathrm{B}_{4} \mathrm{C}\right)$ mixed in dielectric fluid on EDM of Inconel X-750 alloy. The process parameters selected as discharge current $\left(\mathrm{I}_{\mathrm{p}}\right)$, pulse on time $\left(\mathrm{T}_{\text {on }}\right)$, pulse off time $\left(\mathrm{T}_{\text {off }}\right)$, boron carbide $\left(\mathrm{B}_{4} \mathrm{C}\right)$ powder concentration to examine their performance responses on Material Removal Rate (MRR), Surface Roughness(Ra) and Recast Layer Thickness (RLT).In this study, o examine the process parameters which influence the EDM process during machining of Inconel X-750 alloy using combined techniques of Taguchi and similarity to ideal solutions (TOPSIS).Analysis of variance (ANOVA) was conducted on multi-optimization technique of Taguchi-TOPSIS. ANOVA results identified the best process parameters and their percentages. It developed the mathematical equation on Taguchi-TOPSIS performance characteristics results. The multi optimization results indicated that $I_{p}$ and $T_{\text {off }}$ are more significant parameters; $V$, and $T_{\text {on }}$ parameters are less significant. Finally, surface structures were studied at optimized EDM conditions by using scanning electron microscope (SEM).
\end{abstract}

KEYWORDS: $\mathrm{B}_{4} \mathrm{C}$ powder, Taguchi $\mathrm{L}_{27}$ orthogonal array, Multi-optimization, Inconel X-750, TOPSIS

\section{Introduction}

The advanced materials are in need of different industries for manufacturing of complex structures and products. It is impossible to find sufficiently hard tools to machine aforesaid materials at economic cutting speeds. Materials possessing excellent metallurgical characteristics are difficult to machine using conventional methods. The degree of accuracy and the surface finish is poor and uneconomical in conventional machining. To cutting the advanced materials to intricate and required shapes the method of unconventional machining is used to enhance the material removal rate (MRR). Among these technologies electrical discharge machining (EDM) is one of the best unconventional method used in manufacturing industries to machine any electrically conductive material into required shape with accurate precision. The working principle of EDM process is based on an interrupted electric spark discharges between the electrode (cathode) and the workpiece (anode). Due to the high temperature (above $12000^{\circ} \mathrm{C}$ ) of spark in the machining gap $(0.2 \mathrm{~mm})$ the material is removed from the workpiece with the replica of the tool. The thermoelectric energy is produced between work piece and an electrode immersed in dielectric fluid with conduction of electric current. The powder mixed EDM process powder particles are interrupted the spark and distributed equal space on the workpiece surface that while effects the machining. It is an emergent method to increase the EDM process capabilities and reduces the surface defects; deteriorate surface roughness with produced minor surface cracks on the machined surface [1$3]$. 
Various researchers have done experimentation on machining of various materials using different optimization techniques to enhance the performance characteristics of PMEDM process namely MRR, SR, and RLT. Jyothimurugan et al. examined the different dielectric fluids mixed into the EDM oil for machining of Monel 400 alloy. It was identified that concentration of kerosene and servotherm oil mixed into EDM process significantly improves the MRR, Ra and TWR than with conventional dielectric fluids [4]. Kuraichen et al.studied the $\mathrm{SiC}$ particle in dielectric fluid on EDM of Ti-6Al-4V alloy. They revealed that use of 5 $\mathrm{g} / \mathrm{L}$ of $\mathrm{SiC}$ powder concentration, $0.1 \mu \mathrm{F}$ capacitance and voltage of $115 \mathrm{~V}$ were considered increase the MRR and decreasing the TWR [5].Tiwary et al. examined the use of different powders into dielectric fluid on EDM process. The adopted powder were copper $(\mathrm{Cu})$, nickel (Ni) and cobalt ( $\mathrm{Co}$ ) added into dielectric fluid on performance characteristics as MRR, TWR, $\mathrm{OC}$ and TA. The authors was identified in their experimental investigation the $\mathrm{Cu}$ powder mixed deionized water concentration increase the MRR than the other powders [6]. Yadav et al. had done an experimental investigation by addition of oxygen gas in the dielectric fluid for machining of AISI M2 grade high speed steel using rotary tool near-dry EDM. They found that oxygen mixture in the dielectric results in the increase of MRR [7].

Murahari Kolli and Kumar Adepu examined the $\mathrm{B}_{4} \mathrm{C}$ powder added in electronica 450 dielectric fluid on EDM process of Ti-6Al-4V alloy. The author's reported that when adding the $\mathrm{B}_{4} \mathrm{C}$ powder the results were observed that enhance the MRR and decreasing the TWR and RLT. Same co-authors optimized EDM process parameters with the help of Taguchi technique. Span 20 surfactant and $\mathrm{B}_{4} \mathrm{C}$ powder, current, pulse on time and pulse off time has the important parameters. $\mathrm{B}_{4} \mathrm{C}$ and span 20 surfactant concentrations have the important contribution to the performance characteristics of MRR, SR and RLT [8-9 Silicon, SAGE]. Gangadharuda Talla et al. utilized the multi response optimization of PMEDM of Al-MMCs using GRA. The optimum conditions of process parameters are done by using multi response optimization of GRA to get maximum MRR and lower SR. They reported that $6 \mathrm{~g} / \mathrm{L}$ graphite powder mixed into dielectric fluid it gives the maximum results [10]. Chethan Roy et al. studied the machinability of $\mathrm{Al} / 10 \% \mathrm{SiC} / 2.5 \% \mathrm{TiB}_{2} \mathrm{MMC}^{\prime}$ s with PMEDM by using RSM. They also studied the effects of the process parameters like pulse current (I), pulse on-time (Ton) and concentration of the $\mathrm{Al}$ powder in kerosene dielectric (C) and their effects on MRR, TWR and Ra. They concluded that desirability function approach gives the optimum process parameters to achieve higher MRR, lower TWR and Ra.They concluded that addition of $\mathrm{Al}$ powder in the dielectric fluid gives the SR to a value of $3.31 \mu \mathrm{m}$ [11].

Rajesh Kumar Bhuyan et al. investigated the multi optimization of the process parameter by using TOPSIS method for $\mathrm{Al}-24 \% \mathrm{SiC}$ MMCs using EDM. The effect of process parameters for peak current, pulse on time and flushing pressure on the responses like MRR, TWR and $\mathrm{Ra}$ are considered. They conducted and designed the experiments using BoxBehnken Central composite design method [12]. Nathan Kumar et al. investigated the mechanical properties and EDM performance characteristics like MRR and TWR in EDM machining process of A12618 alloy reinforced with $\mathrm{Si}_{3} \mathrm{n}_{4}, \mathrm{ALN}$ and $\mathrm{ZrB}_{2}$ composites. They reported that machining characteristics of hybrid composites is analyzed with design of Taguchi experimentation. The results showed that Al 2618 composites had improved the mechanical properties. They conducted the ANOVA test to determine the influence of process parameters on the responses like MRR and TWR[13].

Rajesh Khanna et al. investigated multiple performance characteristics optimization for Al 7075 alloy on EDM by Taguchi grey relational theory. It has been observed that the ANOVA result indicates that the pulse on time and pulse off time are significant factors on the MRR. The optimization results showed that the combination of maximum pulse on-time and minimum pulse off-time gives maximum MRR [14]. Murahari Kolli and Kumar Adepu 
investigated the surfactant in dielectric fluid on EDM process using Taguchi-GRA approach. They observed that the ANOVA results of Taguchi-GRA approach; current, surfactant concentration and pulse on time has significant parameters [15]. Wang et al. optimized the process parameters of rotary EDM using Taguchi methodology while drilling of $6061 \mathrm{Al} / \mathrm{Al}_{2} \mathrm{O}_{3}$ composite. During their work they observed that polarity and peak current has significant factors on the performance characteristics on MRR and SR [16].

From the literature survey, it was noticed that the mixture of powder particles in the dielectric fluid on performance responses improves the surface characteristics. Very few coauthors have attempted to machine the Inconel X-750 alloy using $\mathrm{B}_{4} \mathrm{C}$ powder concentration. Hence, there is a need to study the use of $\mathrm{B}_{4} \mathrm{C}$ powder concentration to machine the $\mathrm{X}-750$ alloy. In the present investigation to examine the process parameters which influence the PMEDM process during machining of Inconel X-750 alloy using combined techniques of Taguchi TOPSIS approach. Initially, Taguchi L27orthogonal array (OA) is used for conducting the experiments. Based on the experimental results and ANOVA analysis, the level of influence of process variables and performance results on MRR, SR and RLT was analyzed. Further, TOPSIS multi response optimization method was adopting applied to select the most important parameter levels to get the maximum MRR, minimum SR and RLT. Further, it's identifying the best process parameters on the performance characteristics of PMEDM process. Finally, the surface characteristics are studied using SEM analysis.

\section{EXPERIMENTAL METHODS}

Inconel X-750 alloy and tungsten copper of $16 \mathrm{~mm}$ diameter are used as the workpiece and tool electrodes selected the study. The experiments are conducted on die-sinking CNC EDM machine. Spark erosion EDM SAE 40 oil used as dielectric fluid. The self fabricated dielectric system is designed with attached to the EDM machine as shown in the Fig.1. The fresh dielectric fluid with various concentration of $\mathrm{B}_{4} \mathrm{C}$ powder is used for conducting the experiment. The $\mathrm{B}_{4} \mathrm{C}$ powder particles shape and sizes are observed in the SEM image as shown in the Fig.2.

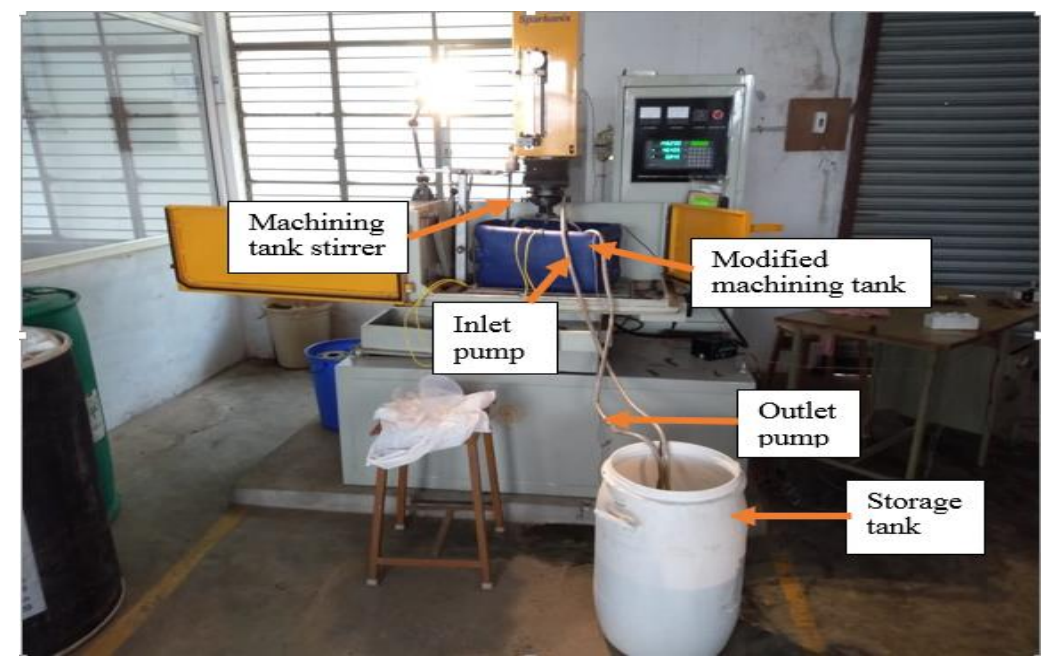

Fig. 1 Modified EDM experimental set

At pilot experiments the $\mathrm{B}_{4} \mathrm{C}$ powder is mixed in the dielectric fluid at different weights i.e. $2 \mathrm{~g} / \mathrm{L}$ to $10 \mathrm{~g} / \mathrm{L}$. Similar manner performed the pilot experiments in discharge current, pulse on time, pulse off time and voltage with their corresponding values. The process parameters and their levels of PMEDM are observed in the Table 1.Each experiment is conducted three 
trails at a depth of cut of $0.5 \mathrm{~mm} . \mathrm{I}_{\mathrm{p}}, \mathrm{T}_{\mathrm{on}}, \mathrm{T}_{\mathrm{off}}$ and $\mathrm{B}_{4} \mathrm{C}$ powder concentration are selected as process parameters to explore their performance responses on MRR,SR and RLT.

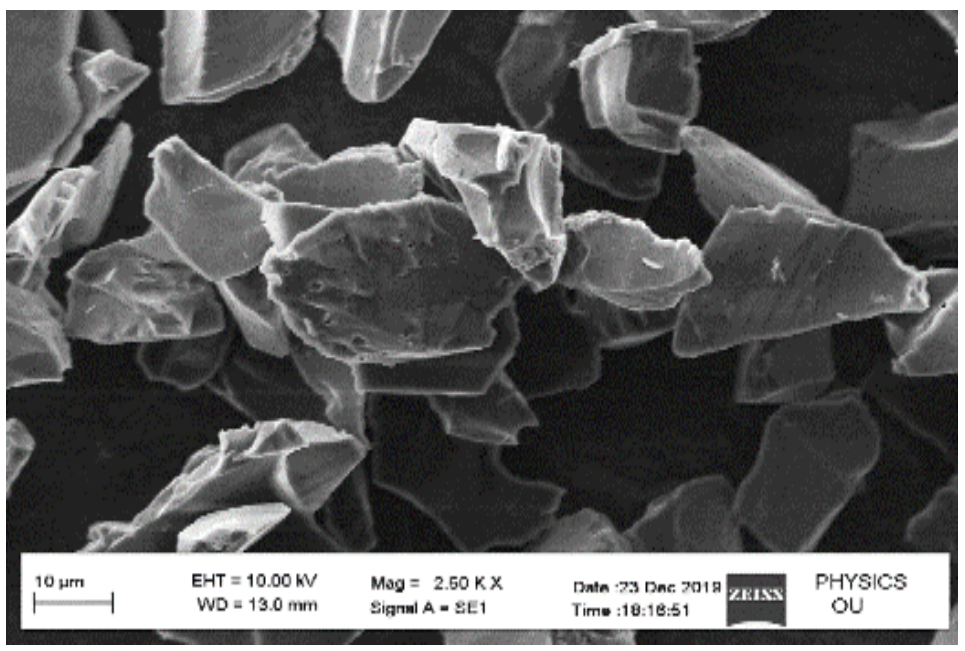

Fig. 2 SEM image of $\mathrm{B}_{4} \mathrm{C}$ powder particles

EDM is a process in which there is more number of input factors being used. For designing the experiments Taguchi's orthogonal array (OA) model was considered. It is a technique used to design the experiments (DoE), analyze the results and reduce the number of experiments for achieving good quality products. Taguchi technique was being used by many of the industries and researchers from many years [17]. In this experiment $\mathrm{L}_{27} \mathrm{OA}$ was utilized for designing the experiments Table 2 shows the experimental layout. Before starting the experiments, the work piece was clamped to the machine. The workpiece and tool were connected to the particular terminals of the power supply.

Table 1. Process parameters and their levels

\begin{tabular}{lccccc} 
& Symbol & Parameters & Units & \multicolumn{2}{c}{ Levels } \\
& & & $\mathbf{1}$ & $\mathbf{2}$ & $\mathbf{3}$ \\
\hline $\mathrm{I}_{\mathrm{p}}$ & Discharge Current & Amps & 8 & 12 & 16 \\
$\mathrm{~T}_{\text {on }}$ & Pulse- on- time & $\mu \mathrm{s}$ & 20 & 60 & 100 \\
$\mathrm{~T}_{\text {off }}$ & Pulse- off- time & $\mu \mathrm{s}$ & 20 & 30 & 40 \\
$\mathrm{~B}_{4} \mathrm{C}$ & B 4 C powder con. & $\mathrm{g} / \mathrm{L}$ & 2 & 6 & 10 \\
\hline
\end{tabular}

Once the connections were ensured, machine was made on and experiments were performed in order to cut the unwanted material and get the required slots on the surface of the workpiece. MRR is measured using electronic weighing balance. SR is measured using the instrument Tally surf at five distinct locations and the average value is noted. After conducting experiments, the EDMed samples are cut using EDM process. For SEM analysis the samples are prepared using polishing operation to remove the effect of EDM process. To measure the recast layer, thickness the Inconel X-750 specimens are polished with various grade emery papers. Finally, the samples are polished by diamond polishing using alumina diamond paste. The properly polished specimens are etched with HCL, acetic acid and $\mathrm{HNO}_{3}$.

\section{RESULTS AND DISCUSSION}

The experiments are designed and planned with Taguchi $\mathrm{L}_{27}$ orthogonal array adopted the MINITAB 18.0statistical software. The responses of each process parameters were identified and their percentages on the output responses are determined using ANOVA. The S/N ratio values are analyses with the considered results are indicated in Table 3. 


\subsection{Effect of process parameters on MRR}

The effect of process parameters like $\mathrm{Ip}, \mathrm{T}_{\mathrm{on}}, \mathrm{T}_{\text {off }}$ and $\mathrm{B}_{4} \mathrm{C}$ powder concentration are observed in the S/N ratio plots of MRR during machining of Inconel X750.From the 2D plots for $\mathrm{S} / \mathrm{N}$ ratios, it was identified there is an increase in MRR gradually with from $8 \mathrm{~A}$ to 16Awith the increase in the $I_{p} i$.eas shown in the Fig.3. At highest values of $I_{p}$ generates more $\mathrm{I}_{\mathrm{p}}$ densities results in high thermal energy generating in the machining zone, it results increase in the MRR. When $\mathrm{B}_{4} \mathrm{C}$ mixed in dielectric fluid enhances the MRR at $2 \mathrm{~g} / \mathrm{L}$ to $10 \mathrm{~g} / \mathrm{L}$, due to the fact that the $\mathrm{B}_{4} \mathrm{C}$ powder added into the dielectric fluid equal dispersion of the discharge energyin the machined zone, it results in higher rate of MRR.

Table 2. Taguchi $\mathrm{L}_{27}$ Experimental Layout

\begin{tabular}{|c|c|c|c|c|}
\hline S.no & $\mathbf{I}_{\mathbf{p}}$ & $\mathbf{T}_{\text {on }}$ & $\mathbf{T}_{\text {off }}$ & $\begin{array}{c}\mathrm{B}_{4} \mathrm{C} \text { Powder } \\
\text { con. }\end{array}$ \\
\hline 1 & 8 & 20 & 20 & 2 \\
\hline 2 & 8 & 20 & 30 & 6 \\
\hline 3 & 8 & 20 & 40 & 10 \\
\hline 4 & 8 & 60 & 20 & 6 \\
\hline 5 & 8 & 60 & 30 & 10 \\
\hline 6 & 8 & 60 & 40 & 2 \\
\hline 7 & 8 & 100 & 20 & 10 \\
\hline 8 & 8 & 100 & 30 & 2 \\
\hline 9 & 8 & 100 & 40 & 6 \\
\hline 10 & 12 & 20 & 40 & 2 \\
\hline 11 & 12 & 20 & 20 & 6 \\
\hline 12 & 12 & 20 & 30 & 10 \\
\hline 13 & 12 & 60 & 40 & 6 \\
\hline 14 & 12 & 60 & 20 & 10 \\
\hline 15 & 12 & 60 & 30 & 2 \\
\hline 16 & 12 & 100 & 40 & 10 \\
\hline 17 & 12 & 100 & 20 & 2 \\
\hline 18 & 12 & 100 & 30 & 6 \\
\hline 19 & 16 & 20 & 30 & 2 \\
\hline 20 & 16 & 20 & 40 & 6 \\
\hline 21 & 16 & 20 & 20 & 10 \\
\hline 22 & 16 & 60 & 30 & 6 \\
\hline 23 & 16 & 60 & 40 & 10 \\
\hline 24 & 16 & 60 & 20 & 2 \\
\hline 25 & 16 & 100 & 30 & 10 \\
\hline 26 & 16 & 100 & 40 & 2 \\
\hline 27 & 16 & 100 & 20 & 6 \\
\hline
\end{tabular}


Table 3. Taguchi $\mathrm{L}_{27}$ with experimental results

\begin{tabular}{|c|c|c|c|c|c|c|c|}
\hline S.no & $\mathbf{I}_{\mathbf{p}}$ & $\mathbf{T}_{\text {on }}$ & $\mathbf{T}_{\text {off }}$ & $\begin{array}{c}\text { B4C Powder } \\
\text { con. }\end{array}$ & $\begin{array}{c}\text { MRR } \\
(\mathrm{mm3} / \mathrm{min})\end{array}$ & $\begin{array}{c}\text { SR } \\
(\mu \mathrm{m})\end{array}$ & $\begin{array}{l}\text { RLT } \\
(\mu \mathrm{m})\end{array}$ \\
\hline 1 & 8 & 20 & 20 & 2 & 12.2345 & 3.77 & 10.44 \\
\hline 2 & 8 & 20 & 30 & 6 & 13.8820 & 3.69 & 8.14 \\
\hline 3 & 8 & 20 & 40 & 10 & 17.6543 & 3.65 & 7.98 \\
\hline 4 & 8 & 60 & 20 & 6 & 20.6908 & 4.52 & 11.23 \\
\hline 5 & 8 & 60 & 30 & 10 & 21.6785 & 4.29 & 12.59 \\
\hline 6 & 8 & 60 & 40 & 2 & 19.4108 & 4.31 & 16.35 \\
\hline 7 & 8 & 100 & 20 & 10 & 11.3421 & 4.23 & 14.08 \\
\hline 8 & 8 & 100 & 30 & 2 & 10.2912 & 4.94 & 15.86 \\
\hline 9 & 8 & 100 & 40 & 6 & 8.1532 & 4.59 & 12.49 \\
\hline 10 & 12 & 20 & 40 & 2 & 27.3036 & 4.23 & 16.18 \\
\hline 11 & 12 & 20 & 20 & 6 & 24.3436 & 4.09 & 18.01 \\
\hline 12 & 12 & 20 & 30 & 10 & 26.7643 & 4.39 & 15.92 \\
\hline 13 & 12 & 60 & 40 & 6 & 37.4566 & 4.6 & 18.17 \\
\hline 14 & 12 & 60 & 20 & 10 & 31.4632 & 4.72 & 15.85 \\
\hline 15 & 12 & 60 & 30 & 2 & 32.9756 & 4.79 & 19.36 \\
\hline 16 & 12 & 100 & 40 & 10 & 31.6723 & 4.84 & 19.70 \\
\hline 17 & 12 & 100 & 20 & 2 & 21.7180 & 4.93 & 19.08 \\
\hline 18 & 12 & 100 & 30 & 6 & 26.1987 & 5.37 & 20.67 \\
\hline 19 & 16 & 20 & 30 & 2 & 29.5732 & 4.93 & 18.48 \\
\hline 20 & 16 & 20 & 40 & 6 & 38.6732 & 4.43 & 19.11 \\
\hline 21 & 16 & 20 & 20 & 10 & 24.8976 & 4.12 & 15.32 \\
\hline 22 & 16 & 60 & 30 & 6 & 46.2098 & 4.76 & 21.51 \\
\hline 23 & 16 & 60 & 40 & 10 & 49.6549 & 4.12 & 19.53 \\
\hline 24 & 16 & 60 & 20 & 2 & 35.1084 & 5.12 & 24.42 \\
\hline 25 & 16 & 100 & 30 & 10 & 35.1254 & 5.23 & 22.33 \\
\hline 26 & 16 & 100 & 40 & 2 & 42.0140 & 5.65 & 24.30 \\
\hline 27 & 16 & 100 & 20 & 6 & 33.8123 & 5.02 & 22.20 \\
\hline
\end{tabular}

There is an increase in MRR with the increase of $\mathrm{T}_{\text {on }}$ from $20 \mu$ s to $60 \mu$ s and beyond there is decrease in trend was observed that to more amount of heat generated in the working gap results material surface is slurry type nature occur. There is an increase in MRR was observed as the $\mathrm{T}_{\text {off }}$ is increased from $20 \mu \mathrm{s}$ to $40 \mu$ s due to remove the unwanted particles on the both materials surfaces and it to produce more ions transformation to next spark initiation. The significance of the process parameters affecting the MRR can be observed from ANOVA tables for $\mathrm{S} / \mathrm{N}$ ratios as shown in the Table 4 . The important observations are found from $\mathrm{P}$ values and F-values. The values which are greater than 0.100 indicates that the model terms are not significant. In this MRR model $\mathrm{I}_{\mathrm{p}}, \mathrm{T}_{\mathrm{on}}$ and $\mathrm{T}_{\mathrm{off}}$ is most significant terms. The value of $\mathrm{R}^{2}$ and $\mathrm{R}^{2}$ (pred) for MRR models are $98.6 \%$ and $94.1 \%$ respectively. 


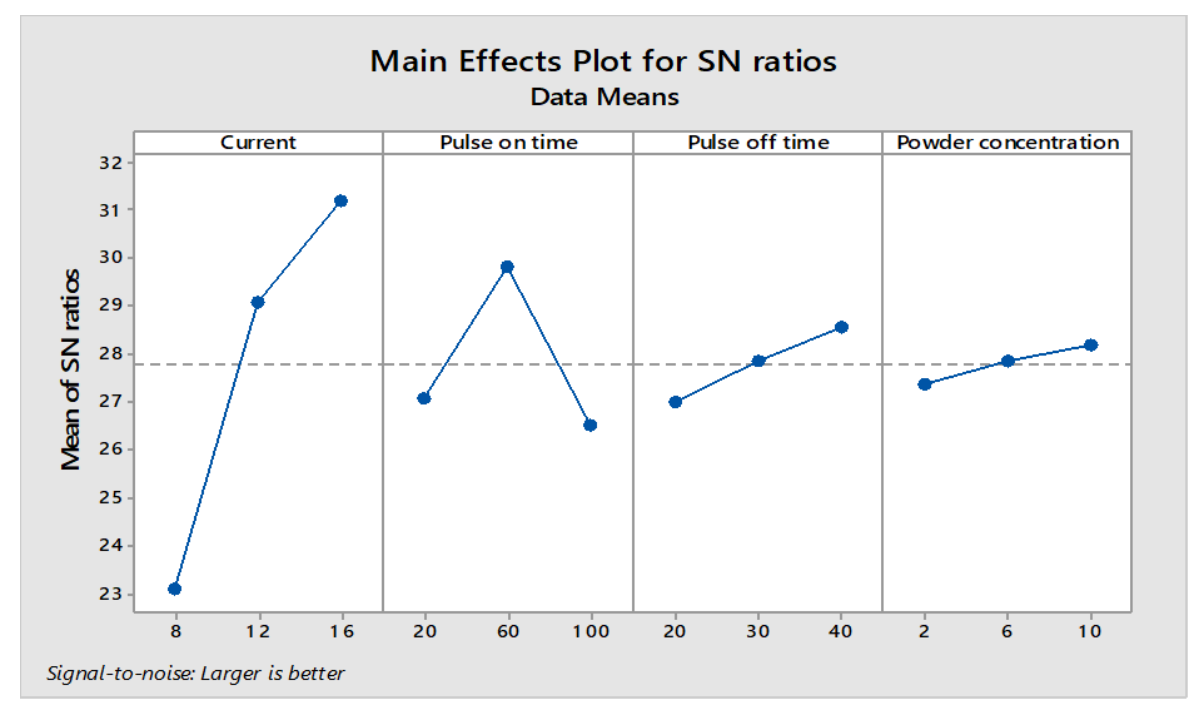

Fig. 3 Effect of process parameters on the $\mathrm{S} / \mathrm{N}$ ratio of MRR

Table 4. Analysis of variance ANOVA of MRR

\begin{tabular}{lcccccc}
\hline \multicolumn{1}{c}{ Source } & DF & Seq SS & Adj MS & F & P & \%Cont \\
\hline Ip & 2 & 318.152 & 159.076 & 162.86 & 0.000 & 73.40 \\
Ton & 2 & 56.238 & 28.119 & 28.79 & 0.001 & 12.97 \\
Toff & 2 & 10.804 & 5.402 & 5.53 & 0.043 & 2.49 \\
B4C Powder con. & 2 & 2.975 & 1.487 & 1.52 & 0.292 & 0.68 \\
Ip * Ton & 4 & 28.083 & 7.021 & 7.19 & 0.018 & 6.47 \\
Ip * B 4 C Powder & 4 & 6.309 & 1.577 & 1.61 & 0.285 & 1.45 \\
con. & & & & & & \\
Ton * B4C Powder & 4 & 4.991 & 1.248 & 1.28 & 0.375 & 1.15 \\
con. & & & & & & 1.35 \\
Residual Error & 6 & 5.861 & 0.977 & & & 100.00 \\
Total & 26 & 433.412 & & &
\end{tabular}

\subsection{Effect of process parameters of SR}

$\mathrm{SR}$ results and corresponding values of $\mathrm{S} / \mathrm{N}$ ratios whose analyses are listed in the Table 3. From the plots of SR as shown in the Fig.4 it was identified that SR increases uniformly with the addition of $\mathrm{B}_{4} \mathrm{C}$ particles in the dielectric fluid. The increase in $\mathrm{SR}$ value is due to the high amount of spark energy which indicates the huge amount of bombarding material results in wider and deep craters are occurred results in degraded the surface finish. The $T_{\text {on }}$ increases with degraded the surface finish because of more amount of time discharge energy and density is supplied to the material surfaces that results on voids and cracks are formed[21]. As the $\mathrm{T}_{\text {off }}$ increases from $20 \mu \mathrm{s}$ to $40 \mu \mathrm{s}$, the $\mathrm{SR}$ reduces. The increase in the $\mathrm{T}_{\text {off }}$ results in undesirable heat loss and more time to flush away the debris. This leads to drop in temperature of the workpiece surface before the next spark occurs. Thus, reduces the crater size, improves the SR.

It was noticed that $\mathrm{SR}$ increases when the particles are added in fluid gradually. When $\mathrm{B}_{4} \mathrm{C}$ particles are mixed in the dielectric fluid reduces the insulation strength, results in the decrease of electrical resistivity and therefore the machining gap increases. 


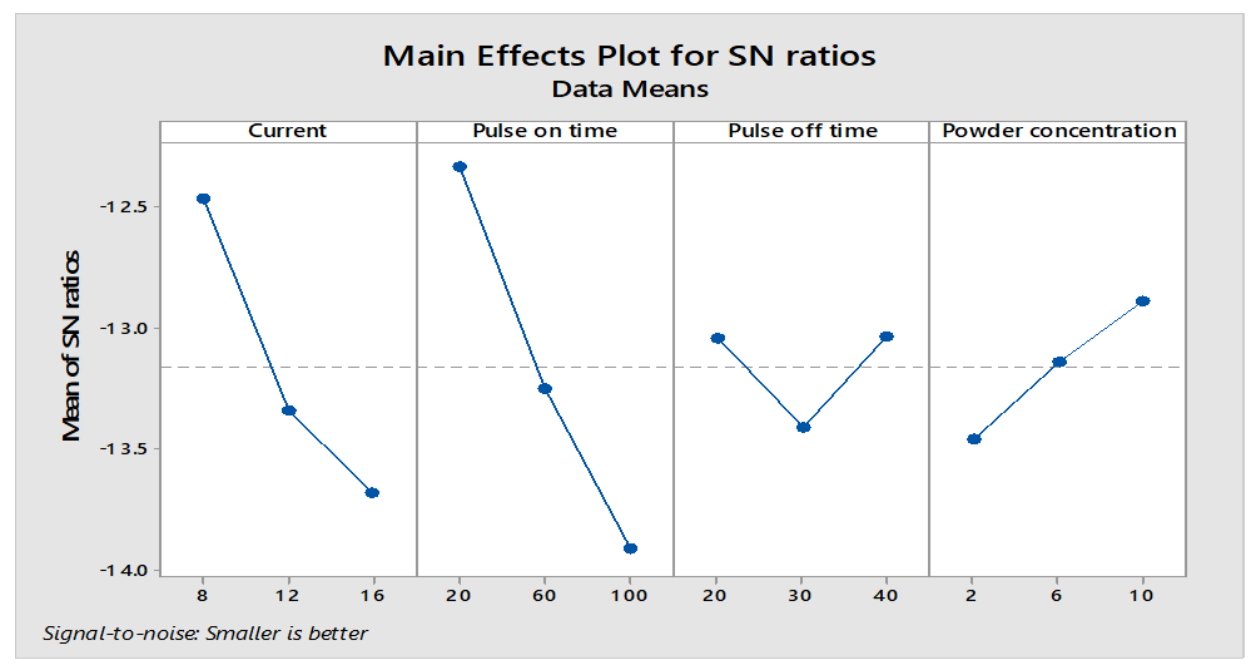

Fig. 4 Effect of process parameters on the $\mathrm{S} / \mathrm{N}$ ratio of SR

Due to this large gap the plasma generated is high on the surface of the sample. The surface finish is less due irregular shapes of craters and debris particles [8].

Table 5. Analysis of variance (ANOVA) of SR

\begin{tabular}{lcccccc}
\hline \multicolumn{1}{c}{ Source } & DF & Seq SS & Adj MS & F & P & \%Cont \\
\hline $\mathrm{I}_{\mathrm{p}}$ & 2 & 1.88147 & 0.94074 & 27.36 & 0.001 & 29.19 \\
$\mathrm{~T}_{\text {on }}$ & 2 & 3.06725 & 1.53363 & 44.60 & 0.000 & 47.59 \\
$\mathrm{~T}_{\text {off }}$ & 2 & 0.23472 & 0.11736 & 3.41 & 0.102 & 3.64 \\
$\mathrm{~B}_{4}$ C Powder con. & 2 & 0.43852 & 0.21926 & 6.38 & 0.033 & 6.80 \\
$\mathrm{I}_{\mathrm{p}} * \mathrm{~T}_{\text {on }}$ & 4 & 0.17421 & 0.04355 & 1.27 & 0.378 & 2.70 \\
$\mathrm{I}_{\mathrm{p}} * \mathrm{~B}_{4}$ C Powder con. & 4 & 0.38661 & 0.09665 & 2.81 & 0.125 & 5.99 \\
$\mathrm{~T}_{\text {on }}{ }^{*} \mathrm{~B}_{4}$ C Powder & 4 & 0.05570 & 0.01393 & 0.40 & 0.800 & 0.86 \\
con. & & & & & & \\
Residual Error & 6 & 0.20631 & 0.03439 & & & 3.20 \\
Total & 26 & 6.44479 & & & & 100.00 \\
\hline
\end{tabular}

ANOVA results of SR presented in the Table 5 describe process significance of input parameters on SR, which is as follows. The values of $R^{2}(96.6 \%)$ and adj $R^{2}(91.1)$ of the model are within variability range of predicating $R a$ values.

\subsection{Effect of process parameters on Recast layer thickness (RLT)}

The white layer is formed when the molten metal from the work piece is not properly flushed out from the spark zone but it resolidify on the surface of the workpiece. The WLT was measured using the image analyzer software and their $\mathrm{S} / \mathrm{N}$ ratio values are shown in Table 6. From the $\mathrm{S} / \mathrm{N}$ ratio plots as shown inFig.5 it was identified that significantly increase in RLT with increase in $\mathrm{I}_{\mathrm{p}}$.

It was noticed that $I_{p}$ was enhances with enhance in the current flow rate which influence the more material is melting and solidifies. Normally, when applied the discharge energy not only melt the material it generated impulsive forces in the discharge gap, it results the formation of an uneven WLT. The increase of $\mathrm{T}_{\text {on }}$ from $20 \mu \mathrm{s}$ to $100 \mu \mathrm{s}$ as shown in the Fig 5 results in the increase of RLT. At initial condition of $\mathrm{T}_{\text {on }}$ less amount of WLT was formed due to fact that energy transferred to the tool material to workpiece material is also less that effect minimum MRR and solidification occurs at the material surface. It was observed that WLT was lower at lower condition of $\mathrm{T}_{\text {off. }}$ The $\mathrm{T}_{\text {off }}$ was insignificant parameter which influences the machining gap, it removes the unwanted (i.e. tar, debris and accumulated powder) particles 
flushed out and cleaned the electrode surfaces and invites the next spark on the machining gap. The use of powder concentration in the dielectric tank from $2 \mathrm{~g} / \mathrm{L}$ to $10 \mathrm{~g} / \mathrm{L}$, WLT increases as shown in the figure.

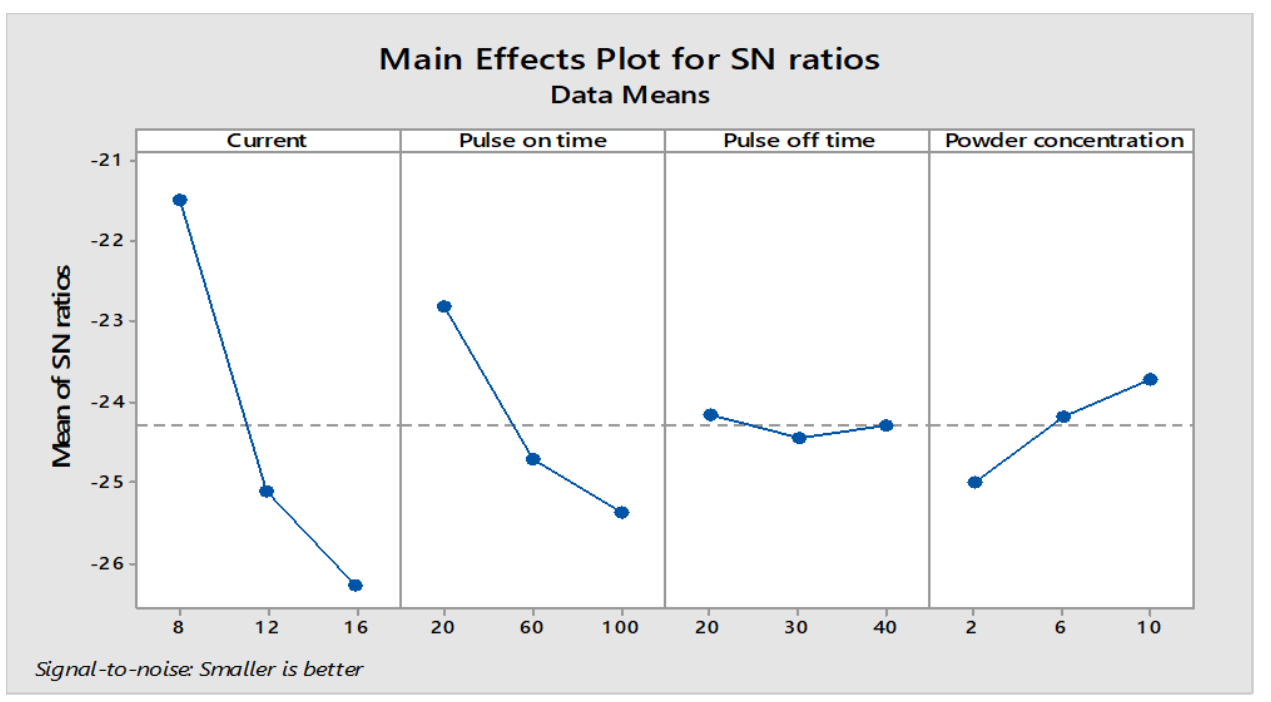

Fig. 5 Effect of process parameters on the S/N ratio of RLT

Table 6. Analysis of variance (ANOVA) of RLT

\begin{tabular}{lcccccc}
\hline \multicolumn{1}{c}{ Source } & DF & Seq SS & Adj MS & F & P & \% Cont \\
\hline $\mathrm{I}_{\mathrm{p}}$ & 2 & 347.467 & 173.734 & 1437.75 & 0.000 & 68.09 \\
$\mathrm{~T}_{\text {on }}$ & 2 & 96.164 & 48.082 & 397.91 & 0.000 & 18.84 \\
$\mathrm{~T}_{\text {off }}$ & 2 & 1.405 & 0.702 & 5.81 & 0.039 & 0.275 \\
$\mathrm{~B}_{4} \mathrm{C}$ Powder con. & 2 & 25.107 & 12.553 & 103.89 & 0.000 & 4.92 \\
$\mathrm{I}_{\mathrm{p}} * \mathrm{~T}_{\text {on }}$ & 4 & 10.388 & 2.597 & 21.49 & 0.001 & 2.03 \\
$\mathrm{I}_{\mathrm{p}} * \mathrm{~B}_{4} \mathrm{C}$ Powder con. & 4 & 15.464 & 3.866 & 31.99 & 0.000 & 3.03 \\
$\mathrm{~T}_{\text {on }} * \mathrm{~B}_{4}$ C Powder & 4 & 13.565 & 3.391 & 28.07 & 0.001 & 2.65 \\
con. & & & & & & \\
Residual Error & 6 & 0.725 & 0.121 & & & 0.14 \\
Total & 26 & 510.285 & & & & 100.00 \\
\hline
\end{tabular}

The important observations are found from P-values and F-values. The values which are greater than 0.100 indicates that the model terms are not significant. In this RLT model $\mathrm{I}_{\mathrm{p}}, \mathrm{T}_{\text {on }}$ and $\mathrm{T}_{\text {off }}$ is most significant terms. The value of $\mathrm{R}^{2}$ and $\mathrm{R}^{2}$ (pred) for RLT models are $97.4 \%$ and $92.6 \%$ respectively.

\subsection{Multi response optimization using TOPSIS technique for machining Inconel X750}

Multi attribute decision making (MADM) is the process of making a judgment based up on the ending individual results. The decision making is an important element to the functioning of a system because, system performance depends more on single performance to a multiple performance which is more efficient and complex to the system. In this paper, TOPSIS method is adopted for multi response optimization for machining of Inconel X750 workpiece which is one of the classical approaches of MADM. The TOPSIS technique was originally developed by Hwang and Yoon [18] in 1981 and it was modernized by Yoon in 1987. The fundamental concept of this technique is to find out the best alternative or appropriate alternative that has the shortest distance position from the positive ideal solution and the faraway distance position from negative ideal solution. One of the main uniqueness of the TOPSIS method is to identify and alternate the bad results in criterion among the other good 
results in alternative criterion. Based on the performance attributes, and alternatives maximum benefit criteria (higher the better) depends on the positive ideal solution, negative ideal solution is gives the adverse criteria (lower the better), but the negative ideal solution minimizes the benefit criteria and maximizes the adverse criteria. In this paper, consider the performance responses maximizing the MRR and minimizing the SR. The following steps are involved on the TOPSIS method.

Step 1: Identified the attributes and alternatives are determined. In this problem the 27 alternatives, 3 attributes considered for the evaluation. MRR is considered as beneficial attributes and maximization (higher the better), as SR and TWR are considered as non beneficial attributes i.e minimization (lower the better).

Step 2: Lan and Tian -Syung[19] suggested that designed a decision matrix with consisting of ' $\mathrm{n}(3)$ ' attributes ' $\mathrm{m}$ (27)' alternatives as shown in Table 7

Step 3: The experimental values (quantify) of EDM performance responses are then normalized using eq (1), as shown in Table 8

$$
x_{i j}=\frac{R_{i j}}{\sqrt{\sum_{i=1}^{n} R_{i j}^{2}}}
$$

Step 4: The weights are assigned based on relative importance of attributes but the sum of weights should be 1 .

Step: 5 The weighted normalized matrix is determined by following equation (2). It is obtained by the product normalized values and weighted values. Table 9 is representing as weighted normalized matrix (Kij)[17].

$$
\mathrm{K}_{\mathrm{ij}}=\mathrm{W}_{\mathrm{j}} \times \mathrm{X}_{\mathrm{ij}}
$$

Step 6: After calculating the weight normalized matrix using equation (2) next step is to obtain the positive ideal solution and negative ideal solution. It is calculating by using equation (3) and (4).

$$
\begin{aligned}
& \left.\left.\mathrm{K}_{\mathrm{j}}^{+}=\left\{\sum_{\mathrm{i}=1}^{\max } \mathrm{K}_{\mathrm{ij}} / \mathrm{j} \in \mathrm{J}, \sum_{\mathrm{i}=1}^{\min } \mathrm{K}_{\mathrm{ij}} / \mathrm{j} \in \mathrm{J}^{\mathrm{l}}\right\} \mathrm{i}=1,2 \ldots \mathrm{m}\right)\right\} \\
& \left.\left.\mathrm{K}_{\mathrm{j}}^{-}=\left\{\sum_{\mathrm{i}=1}^{\min } \mathrm{K}_{\mathrm{ij}} / \mathrm{j} \in \mathrm{J}, \sum_{\mathrm{i}=1}^{\max } \mathrm{K}_{\mathrm{ij}} / \mathrm{j} \in \mathrm{J}^{1}\right\} \mathrm{i}=1,2 \ldots \mathrm{m}\right)\right\} \\
& \mathrm{kj}+\mathrm{MRR}=0.0246 \quad \mathrm{k} \mathrm{j}+\mathrm{TWR}=0.0020 \quad \mathrm{kj}+\mathrm{SR}=0.0098 \\
& \mathrm{k} \mathrm{j}-\mathrm{MRR}=0.0039 \quad \mathrm{k} \mathrm{j}-\mathrm{TWR}=0.0054 \quad \mathrm{kj}-\mathrm{SR}=0.0274
\end{aligned}
$$

Positive ideal solutions for MRR identified as maximum values whereas for SR and RLT are identified as minimum values which are benefit for outcome of the experiment

Table 7 Decision matrix

\begin{tabular}{cccc}
\hline Alternatives & MRR $\left(\mathbf{m m}^{\mathbf{3}} / \mathbf{m i n}\right)$ & $\mathbf{S R}(\mathbf{m m})$ & $\mathbf{R L T}(\mathbf{m m})$ \\
\hline 1. & 12.2345 & 3.77 & 10.44 \\
2. & 13.882 & 3.69 & 8.14 \\
3. & 17.6543 & 3.65 & 7.98 \\
4. & 20.6908 & 4.52 & 11.23 \\
5. & 21.6785 & 4.29 & 12.59 \\
6. & 19.4108 & 4.31 & 16.35
\end{tabular}




$\begin{array}{llll}7 . & 11.3421 & 4.23 & 14.08 \\ 8 . & 10.2912 & 4.94 & 15.86 \\ 9 . & 8.1532 & 4.59 & 12.49 \\ 10 . & 27.3036 & 4.23 & 16.18 \\ 11 . & 24.3436 & 4.09 & 18.01 \\ 12 . & 26.7643 & 4.39 & 15.92 \\ 13 . & 37.4566 & 4.6 & 18.17 \\ 14 . & 31.4632 & 4.72 & 15.85 \\ 15 . & 32.9756 & 4.79 & 19.36 \\ 16 . & 31.6723 & 4.84 & 19.7 \\ 17 . & 21.718 & 4.93 & 19.08 \\ 18 . & 26.1987 & 5.37 & 20.67 \\ 19 . & 29.5732 & 4.93 & 18.48 \\ 20 . & 38.6732 & 4.43 & 19.11 \\ 21 . & 24.8976 & 4.12 & 15.32 \\ 22 . & 46.2098 & 4.76 & 21.51 \\ 23 . & 49.6549 & 4.12 & 19.53 \\ 24 . & 35.1084 & 5.12 & 24.42 \\ 25 . & 35.1254 & 5.23 & 22.33 \\ 26 . & 42.014 & 5.65 & 24.3 \\ 27 . & 12.2345 & 5.02 & 22.2\end{array}$

Then maximum and minimum values are taking from positive and negative solution.

Step 7: The S+ and S- values calculated using the following equations 5 and 6.

$$
\begin{aligned}
& S_{i}^{+}=\sqrt{\sum_{j=1}^{n}\left(K_{i j}-K_{j}^{+}\right)^{2}}, \& i=1,2,3 \ldots \ldots \ldots \ldots \ldots \ldots . m \\
& S_{i}^{-}=\sqrt{\sum_{j=1}^{n}\left(K_{i j}-K_{j}^{-}\right)^{2}}, \& i=1,2,3 \ldots \ldots \ldots \ldots \ldots \ldots . m
\end{aligned}
$$

$\mathrm{Si}+$ denotes positive ideal solution

Si- denotes negative ideal solution

Step 8: for every alternative, closeness coefficient values were determined using the equations (7)

$$
\mathrm{C}_{\mathrm{i}}^{*}=\left(\frac{\mathrm{S}_{\mathrm{i}}^{-}}{\left(\mathrm{S}_{\mathrm{i}}^{+}+\mathrm{S}_{\mathrm{i}}^{-}\right)}\right)
$$

The larger the $\mathrm{Ci}^{*}$ value the better is the performance of the alternatives. The separation measure of positive, negative ideal solution and relative closeness value are mentioned in the Table 10. 
Table 8 Normalized Decision matrix

\begin{tabular}{cccc}
\hline Alternatives & MRR & SR & RLT \\
\hline 1. & 0.080862 & 0.157908 & 0.114349 \\
2. & 0.091751 & 0.154558 & 0.089157 \\
3. & 0.116684 & 0.152882 & 0.087404 \\
4. & 0.136753 & 0.189323 & 0.123002 \\
5. & 0.143281 & 0.179689 & 0.137898 \\
6. & 0.128293 & 0.180527 & 0.179081 \\
7. & 0.074964 & 0.177176 & 0.154217 \\
8. & 0.068018 & 0.206915 & 0.173714 \\
9. & 0.053888 & 0.192255 & 0.136802 \\
10. & 0.18046 & 0.177176 & 0.177219 \\
11. & 0.160896 & 0.171312 & 0.197262 \\
12. & 0.176895 & 0.183877 & 0.174371 \\
13. & 0.247565 & 0.192673 & 0.199015 \\
14. & 0.207952 & 0.1977 & 0.173604 \\
15. & 0.217948 & 0.200632 & 0.212049 \\
16. & 0.209334 & 0.202726 & 0.215773 \\
17. & 0.143542 & 0.206496 & 0.208982 \\
18. & 0.173157 & 0.224925 & 0.226397 \\
19. & 0.19546 & 0.206496 & 0.20241 \\
20. & 0.255606 & 0.185553 & 0.209311 \\
21. & 0.164558 & 0.172568 & 0.167799 \\
22. & 0.305418 & 0.199375 & 0.235598 \\
23. & 0.328188 & 0.172568 & 0.213911 \\
24. & 0.232045 & 0.214454 & 0.267471 \\
25. & 0.232157 & 0.219061 & 0.244579 \\
26. & 0.277686 & 0.236653 & 0.266156 \\
27. & 0.223478 & 0.210265 & 0.243155 \\
\hline
\end{tabular}

Table 9 Determination of weighted normalized matrix

\begin{tabular}{cccc}
\hline Alternatives & MRR & SR & RLT \\
\hline 1. & 0.036307 & 0.029055 & 0.041966 \\
2. & 0.041196 & 0.028439 & 0.032721 \\
3. & 0.052391 & 0.02813 & 0.032077 \\
4. & 0.061402 & 0.034835 & 0.045142 \\
5. & 0.064333 & 0.033063 & 0.050608 \\
6. & 0.057604 & 0.033217 & 0.065723 \\
7. & 0.033659 & 0.0326 & 0.056598 \\
8. & 0.03054 & 0.038072 & 0.063753 \\
9. & 0.024196 & 0.035375 & 0.050206 \\
10. & 0.081026 & 0.0326 & 0.065039 \\
11. & 0.072242 & 0.031521 & 0.072395 \\
12. & 0.079426 & 0.033833 & 0.063994 \\
13. & 0.111157 & 0.035452 & 0.073038 \\
14. & 0.093371 & 0.036377 & 0.063713 \\
15. & 0.097859 & 0.036916 & 0.077822 \\
16. & 0.093991 & 0.037302 & 0.079189 \\
17. & 0.064451 & 0.037995 & 0.076696
\end{tabular}




\begin{tabular}{llll}
18. & 0.077748 & 0.041386 & 0.083088 \\
19. & 0.087762 & 0.037995 & 0.074285 \\
20. & 0.114767 & 0.034142 & 0.076817 \\
21. & 0.073886 & 0.031753 & 0.061582 \\
22. & 0.137133 & 0.036685 & 0.086464 \\
23. & 0.147356 & 0.031753 & 0.078505 \\
24. & 0.104188 & 0.03946 & 0.098162 \\
25. & 0.104239 & 0.040307 & 0.089761 \\
26. & 0.124681 & 0.043544 & 0.097679 \\
27. & 0.100342 & 0.038689 & 0.089238 \\
\hline
\end{tabular}

Table 10: Separation of positive and negative ideal solutions, relative closeness value

\begin{tabular}{|c|c|c|c|c|}
\hline S.no & $\mathrm{Si}^{+}$ & $\mathrm{Si}_{\mathrm{i}^{-}}$ & $\begin{array}{c}\text { Relative } \\
\text { Closeness }\left(C_{i}^{+}\right)\end{array}$ & Rank \\
\hline 1 & 0.111492 & 0.059284 & 0.347144 & 22 \\
\hline 2 & 0.106162 & 0.06928 & 0.394888 & 20 \\
\hline 3 & 0.094965 & 0.073483 & 0.436234 & 16 \\
\hline 4 & 0.087199 & 0.065355 & 0.428406 & 17 \\
\hline 5 & 0.085209 & 0.063105 & 0.425482 & 18 \\
\hline 6 & 0.095987 & 0.047698 & 0.331962 & 23 \\
\hline 7 & 0.116397 & 0.04401 & 0.274365 & 26 \\
\hline 8 & 0.121442 & 0.035414 & 0.225775 & 27 \\
\hline 9 & 0.124699 & 0.048646 & 0.280633 & 25 \\
\hline 10 & 0.074203 & 0.066683 & 0.473311 & 13 \\
\hline 11 & 0.085318 & 0.05583 & 0.395541 & 19 \\
\hline 12 & 0.075271 & 0.065667 & 0.465928 & 14 \\
\hline 13 & 0.055153 & 0.090878 & 0.622322 & 4 \\
\hline 14 & 0.063113 & 0.07761 & 0.551508 & 6 \\
\hline 15 & 0.067969 & 0.076707 & 0.530198 & 7 \\
\hline 16 & 0.071774 & 0.072597 & 0.502853 & 10 \\
\hline 17 & 0.094665 & 0.045957 & 0.32681 & 24 \\
\hline 18 & 0.087311 & 0.055675 & 0.389374 & 21 \\
\hline 19 & 0.07369 & 0.068129 & 0.480393 & 12 \\
\hline 20 & 0.055676 & 0.093526 & 0.626842 & 3 \\
\hline 21 & 0.079256 & 0.062819 & 0.442156 & 15 \\
\hline 22 & 0.055997 & 0.113748 & 0.670112 & 2 \\
\hline 23 & 0.046569 & 0.125276 & 0.729006 & 1 \\
\hline
\end{tabular}




\begin{tabular}{lcccc}
24 & 0.079743 & 0.080097 & 0.501106 & 11 \\
25 & 0.07304 & 0.080548 & 0.524443 & 8 \\
26 & 0.071101 & 0.100487 & 0.585629 & 5 \\
27 & 0.074761 & 0.076821 & 0.506795 & 9 \\
\hline
\end{tabular}

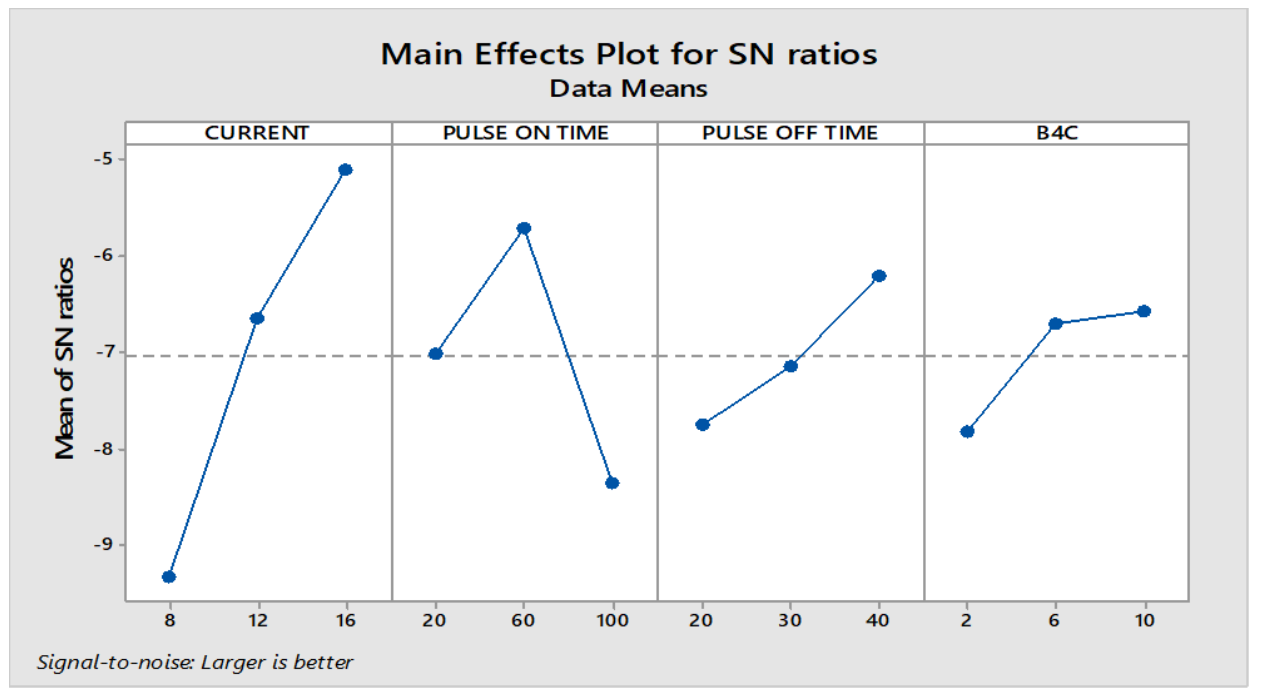

Fig. $6 \mathrm{~S} / \mathrm{N}$ response graph of Taguchi-TOPSIS

\subsection{ANOVA for TOPSIS}

In this section the ANOVA results for multi optimization of TOPSIS technique, are discussed ANOVA results were conducted at 95\% confidence level and 5\% significance level. ANOVA results are indicated in the Table 11 it shows the individual and interaction parameters of multi response parameters. The results of performance responses are calculated of using higher the better expectation adopting MINITAB 17.0 software. It is observed that $I_{p}$ and $\mathrm{T}_{\text {on }}$ play an important role in influencing multi response characteristics at the same time as $\mathrm{T}_{\text {off }}$ and $\mathrm{B}_{4} \mathrm{C}$ contributing to less important role[20]. The values of $\mathrm{R}^{2}(86.9 \%)$ and adj $\mathrm{R}^{2}$ (81.0), of the model are within variability range of predicating $\mathrm{R}^{2}$ values. From the $2 \mathrm{D}$ interaction plots for $\mathrm{S} / \mathrm{N}$ ratios it was identified there is an MRR with an increase in $\mathrm{B}_{4} \mathrm{C}$ powder concentration from $2 \mathrm{~g} / \mathrm{L}$ to $10 \mathrm{~g} / \mathrm{L}$ as shown in the Fig.6.The response table for TOPSIS is shown in the Table 12.

Table 11 ANOVA results of TOPSIS

\begin{tabular}{lccccc}
\hline Source & DF & Seq SS & Adj MS & F & P \\
\hline $\mathrm{I}_{\mathrm{p}}$ & 2 & 82.706 & 82.706 & 32.41 & 0.000 \\
$\mathrm{~T}_{\text {on }}$ & 2 & 31.589 & 31.589 & 12.38 & 0.000 \\
$\mathrm{~T}_{\text {off }}$ & 2 & 10.821 & 10.821 & 4.24 & 0.031 \\
$\mathrm{~B}_{4}$ C Powder con. & 2 & 8.653 & 8.653 & 3.39 & 0.056 \\
Residual Error & 18 & 22.968 & 22.968 & & \\
Total & 26 & 156.737 & & & \\
\hline
\end{tabular}

\subsection{Confirmation Experiments}

The Confirmation experiments are the concluding stages to be verified for the development of output characteristics namely MRR, SR and RLT. Table 13 depicts the conformation test results for the best conditions of PMEDM. The experimental results indicated that optimal 
parameters condition $\mathrm{A}_{3} \mathrm{~B}_{2} \mathrm{C}_{3} \mathrm{D}_{3}$ is suggested than that of initial setting parameters conditions, the error percentage is below $7 \%$ [22-23].

Table 12 Response table for Taguchi- TOPSIS

\begin{tabular}{ccccc}
\hline Parameter & Ip & Ton & Toff & B4C \\
\hline 1 & -9.336 & -7.018 & 7.747 & -7.826 \\
2 & -6.652 & -5.710 & 7.134 & -6.697 \\
3 & -5.099 & -8.359 & -6.207 & -6.564 \\
Delta & 4.237 & 2.649 & 1.540 & 1.262 \\
Rank & 1 & 2 & 3 & 4 \\
\hline
\end{tabular}

Table 13 Conformation experimental results

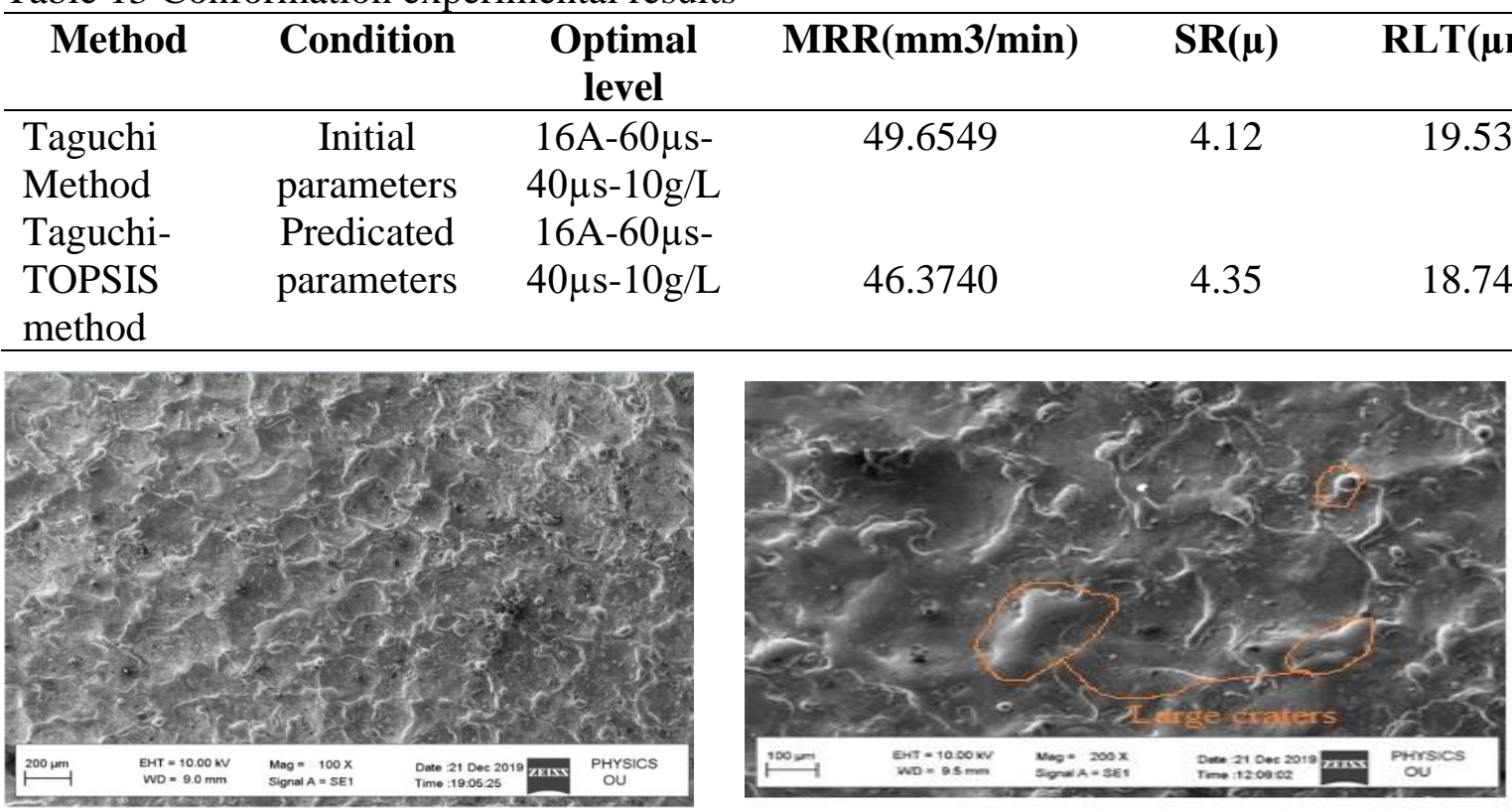

Fig. 7 SEM image on MRR optimum condition Fig. 8 SEM image on SR optimum condition

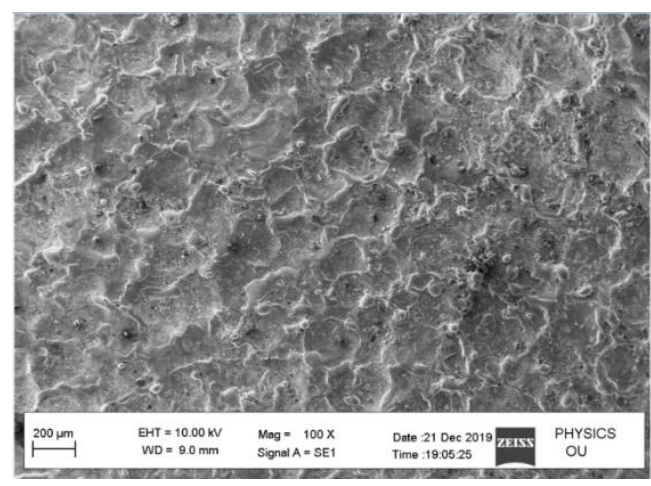

Fig. 9 SEM image on Taguchi-TOPSIS optimum condition

\subsection{SEM micrographs}

The surface topography of the workpiece samples are investigated using Scanning Electron microscope (SEM) as shown in the Fig.7 and 8. SEM images are observed on the machined surface at different conditions. At the optimum conditions $\mathrm{B}_{4} \mathrm{C}$ powder is added in to the dielectric fluid and the surface topography is observed using SEM. At MRR optimum conditions at $\mathrm{I}_{\mathrm{p}}$ of $16 \mathrm{~A}, \mathrm{~T}_{\text {on }} 60 \mu \mathrm{m}, \mathrm{T}_{\text {off }} 40 \mu \mathrm{m}$ and $\mathrm{B}_{4} \mathrm{C} 10 \mathrm{~g} / \mathrm{L}$ added to the dielectric fluid pockmarks, globules of debris, craters are visible on the machined surface. Similarly, 
optimum setting of SR at $\mathrm{I}_{\mathrm{p}}$ of $8 \mathrm{~A}, \mathrm{~T}_{\text {on }} 20 \mu \mathrm{m}, \mathrm{T}_{\text {off }} 20 \mu \mathrm{m}$ and $\mathrm{B}_{4} \mathrm{C} 10 \mathrm{~g} / \mathrm{L}$ mixed into dielectric fluid less voids and micro cracks indicated the surface sample. The variation of the surface samples is observed as the workpiece is machined with two different samples like initial setting and optimal setting as shown in the Fig 9. Fig 10 shows the SEM image machined with RLT at various powder concentration.
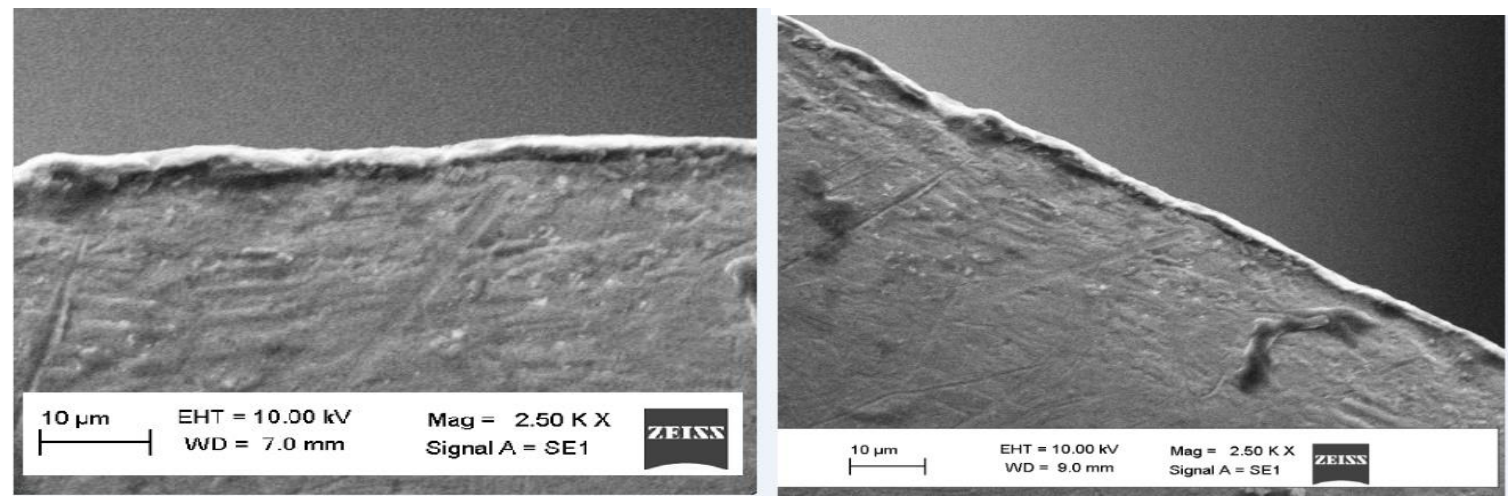

Fig. 10 SEM image of RLT at various powder concentration at $6 \mathrm{~g} / \mathrm{L}$ and $10 \mathrm{~g} / \mathrm{L}$

\section{CONCLUSION}

The present study analyses on a mixture of $\mathrm{B}_{4} \mathrm{C}$ powder into the dielectric fluid and to identify their performance analysis resulted in high MRR, lower SR, and lower RLT. The experimental results are helpful to the multi optimization machining of Inconel X750 using the Taguchi-TOPSIS approach following conclusions that are identified.

- MRR model Ip, Ton, and Toff is most significant terms. The value of $\mathrm{R}^{2}$ and $\mathrm{R}^{2}$ (pred) for MRR models are $98.6 \%$ and $94.1 \%$ respectively.

- SR and RLT performance results were observed that significant factors were Ton, Ip, and $\mathrm{B}_{4} \mathrm{C}$ con.

- The corresponding value recommended through the Taguchi-TOPSIS method indicated that higher input factors were Ip, Ton, and $\mathrm{B}_{4} \mathrm{C}$ powder con., and lower factors were Toff, it will give the best experimental setting for experimental condition 23 and corresponding values of $\mathrm{R}^{2}$ and $\mathrm{R}^{2}$ (pred.) $86.9 \%$ and $81.10 \%$.

- Confirmation experiments are analyzed at the optimum parameters to observe predicted optimum values. The range of percentage error lies below $7 \%$.

- The experimental results indicated that beneficial for the automobile, aerospace, and structural engineering sectors.

\section{REFERENCES}

[1] Ho, K. H., Newman, S. T. "State of the art electrical discharge machining (EDM)", International Journal of Machine Tools and Manufacture 43 (13), pp. 1287 - 1300, 2003.

[2] Manjaiah, M., Narendranath, S., Basavarajappa, S., Gaitonde, V. N. "Effect of electrode material in wire electro discharge machining characteristics of Ti50Ni50xCuxshape memory alloy", Precision Engineering 44, pp. 68 - 77, 2015.

[3] Kolli, M., Kumar, A. "Effect of dielectric fluid with surfactant and graphite powder on Electrical Discharge Machining of titanium alloy using Taguchi method", Engineering Science and Technology, an International Journal 18, pp. 524 - 535, 2015.

[4] Jyothimurugan, R., Amrithagadeswaran, K. S. "Performance of additive mixed kerosene - Sovertherm in Electrical discharge machining of 400", Materials and Manufacturing Processes 31 (4), pp. 432 - 438, 2016. 
[5] Kuraichen, B., Mathew, J. "Effect of power mixed dielectric on material removal and surface modification in micro electric discharge machining of Ti-6AL-4V", Materials and Manufacturing Processes 31(4), pp.439-446, 2016.

[6] Tiwary, A. P., Pradhan, B. B., Bhattacharyya, B. "Influence of various metal powder mixed dielectric on micro-EDM characteristics of Ti-6Al-4V", Materials and Manufacturing Processes 34 (10), pp. 1103 - 1119, 2019.

[7] Yadav, V.K., Kumar, P., Dvivedi, A. "Performance enhancement of rotary tool near-dry EDM of HSS by supplying oxygen gas in the dielectric medium", Materials and Manufacturing Processes 34 (16), pp. 1832 - 1846, 2019.

[8] Kolli, M., Kumar, A. "Assessing the Influence of Surfactant and $\mathrm{B}_{4} \mathrm{C}$ Powder Mixed in Dielectric Fluid on EDM of Titanium Alloy”, Silicon 11 (4), pp. 1731 - 1743, 2019.

[9] Kolli, M., Kumar, A. "Surfactant and graphite powder-assisted electrical discharge machining of titanium alloy", Proceedings of the Institution of Mechanical Engineers, Part B: Journal of Engineering Manufacture 231 (4), pp. 641 - 657, 2017.

[10] Talla, G., Gangopadhyay, S., Biswas, C.K. "Multi response optimization of powder mixed electric discharge machining of aluminum/alumina metal matrix composite using grey relation analysis", Procedia Materials Science 5, pp. 1633 - 1639, 2014.

[11] Roy, C., Syed, K. H., Kuppan, P. "Machinablity of Al/10\% SiC/2.5\% TiB2 Metal Matrix Composite with Powder-mixed Electrical Discharge Machining", Procedia Technology 25, pp. 1056 - 1063, 2016.

[12] Bhuyan, R. K., Routara, B. C., Parida, A. K. "An approach for optimization the process parameter by using TOPSIS Method of Al-24\% SiC metal matrix composite during EDM", Materials Today: Proceedings 2 (4 - 5), pp. 3116-3124, 2015.

[13] Kumar, N.M., Kumaran, S.S., Kumaraswamidhas, L.A. "An investigation of mechanical properties and material removal rate, tool wear rate in EDM machining process of AL2618 alloy reinforced with Si3N4, AlN and ZrB2 composites", Journal of Alloys and Compounds 650, pp.318-327, 2015.

[14] Khanna, R., Kumar, A., Garg, M. P., Singh, A., Sharma, N. "Multiple performance characteristics optimization for Al 7075 on electric discharge drilling by Taguchi grey relational theory", Journal of Industrial Engineering International 11 (4), pp. 459 - 472, 2015.

[15] Kolli, M., Kumar, A. "Optimization of the parameters for the surfactant-added EDM of a Ti-6Al-4V alloy using the Gra-Taguchi method", Materiali in Tehnologije 50 (2), pp. $229-238,2016$.

[16] Wang, C. C., Yan, B. H. "Blind-hole drilling of Al2O3/6061 Al composite using rotary electro-discharge machining", Journal of materials processing technology 102 (1-3), pp. $90-102,2000$.

[17] Ram Prasad, A.V.S., Ramji, K., Kolli, M., Vamsi Krishna, G. "Multi-response optimization of machining process parameters for wire electrical discharge machining of lead-induced Ti-6Al-4V alloy using AHP-TOPSIS method", Journal of Advanced Manufacturing Systems, 18 (02), pp. 213 - 236, 2019.

[18] Yoon, K., Hwang, C. L. "Multiple Attribute Decision Making: Methods and Applications”, Springer: Berlin/Heidelberg, Germany, 1981. 
[19] Lan, T. S. "Taguchi optimization of multi-objective CNC machining using TOPSIS" Information Technology Journal 8 (6), pp. 917 - 922, 2009.

[20] De, D. W., Nandi, T. I., Bandyopadhyay, A. S. "Parametric study for wire cut electrical discharge machining of sintered titanium", Strojnícky časopis - Journal of Mechanical Engineering 69 (1), 17 - 38, 2019. DOI: 10.2478/scjme-2019-0002

[21] Modi, M. A., Agarwal, G. O., Chaugaonkar, S. D., Bhatia, U. M., Patil, V. E. "Effect of machine feed rate on kerf-width, material removal rate, and surface roughness in machining of $\mathrm{Al} / \mathrm{SiC}$ composite material with wire electrical discharge machine", Strojniski Vestnik / Journal of Mechanical Engineering 70(1), pp. 81 - 88, 2020. 